\title{
Tandem Time-of-Flight Mass Spectrometer with High Precursor Ion Selectivity Employing Spiral Ion Trajectory and Improved Offset Parabolic Reflectron
}

\author{
Takaya Satoh, Takafumi Sato, Ayumi Kubo, Jun Tamura \\ JEOL Ltd., 3-1-2 Musashino, Akishima, 196-8558 Tokyo, Japan
}

\begin{abstract}
In this study, we have developed a tandem time-of-flight mass spectrometry (TOF/TOF) technique involving the use of a matrix-assisted laser desorption/ionization ion source that exhibits high precursor ion selectivity. An ion optical system with a $17 \mathrm{~m}$ spiral ion trajectory was used in the first time-of-flight mass spectrometer. High precursor ion selectivity was achieved by realizing a $15 \mathrm{~m}$ flight path, which is considerably longer than that of the conventional MALDITOF/TOF before the precursor ion selection by an ion gate; monoisotopic ions could be selected properly up to $\mathrm{m} / \mathrm{z} 2500$. Furthermore, the first time-of-flight mass spectrometer was composed of electrostatic sectors and could eliminate post-source decay (PSD) ions. Precursor ions with $20 \mathrm{keV}$ kinetic energy were selected and injected into a collision cell, leading to the generation of fragment ions by high-energy collision-induced dissociation (HE-CID). The optimized second time-of-flight mass spectrometer included a post-acceleration region and an offset parabolic reflectron to record product ion spectra in the entire mass range. Our system could generate a simple HE-CID product ion spectrum because each fragment pathway could be observed as a single peak by the selection of monoisotopic ions of all precursor ions and HE-CID fragment pathways could be predominantly observed by the PSD ion elimination.
\end{abstract}

Key words: Spiral ion trajectory, offset parabolic reflectron, TOF/TOF, MALDI

\section{Introduction}

$\mathrm{T}$

ime-of-flight mass spectrometry is a mass spectrometry technique in which the $\mathrm{m} / \mathrm{z}$ values of ions are determined by time measurements. Further, tandem time-of-flight mass spectrometry (TOF/TOF) is a technique in which two time-of-flight mass spectrometers are arranged in tandem and used consecutively [1-14]. Precursor ions are selected by the first time-of-flight mass spectrometer (TOF1), and the fragment ions derived from them are mass analyzed by the second time-of-flight mass spectrometer (TOF2). In recent times, TOF/TOF has often been used with a matrix-assisted laser desorption/ionization (MALDI) source. There are three

Correspondence to: Takaya Satoh; e-mail: taksatoh@jeol.co.jp major ion optical systems for MALDI-TOF/TOF [7-10], and all of them combine a linear time-of-flight mass spectrometer (LTOF) with a reflectron time-of-flight mass spectrometer (RTOF) as the TOF1 and TOF2, respectively. A fragmentation method of the MALDI-TOF/TOF is highenergy collision-induced dissociation (HE-CID) $[15,16]$. The collision energy ranges from 1 to $20 \mathrm{keV}$ (in the laboratory frame); note that this value varies with the ion optical system. With the exception of tandem sector mass spectrometry, MALDI-TOF/TOF is the only instrument capable of observing HE-CID fragment pathways [17]. On the other hand, the ions generated by MALDI often cause post-source decay (PSD) [11-14]. The overlapping of PSD and HE-CID fragment pathways complicates the product ion spectrum. Furthermore, the low precursor ion selectivity of an LTOF and the low resolution of an RTOF make it 
extremely difficult to interpret the product ion spectrum. The problems with MALDI-TOF/TOF are primarily a result of the adoption of a several-hundred-millimeter LTOF as the TOF1.

In this article, we report a newly developed MALDI-TOF/ TOF that shows simple HE-CID pathways on a product ion spectrum. We have adopted a $17 \mathrm{~m}$ long time-of-flight mass spectrometer with a spiral ion trajectory (STOF) [18-20] as the TOF1. The STOF enables the selection of monoisotopic ions from all precursor ions up to $\mathrm{m} / z 2500$. Furthermore, the STOF consisting of electrostatic sectors eliminates the PSD ions. We have also developed a new RTOF for the TOF2, which includes a post-acceleration system and an offset parabolic reflectron (OPR) [21]. The product ion spectra across the entire mass range can be recorded seamlessly by optimizing the mechanical and electric design of the TOF2. Our system displays HE-CID fragment pathways predominantly, and they appear as single peaks on the product ion spectrum.

\section{Instrumentation}

\section{Ion Optical System of the Time-of-Flight Mass Spectrometer with Spiral Ion Trajectory (STOF)}

A schematic of our system is shown in Figure 1. The red line represents an ion trajectory passing through an eight-cycle STOF, a collision cell, and an RTOF that is composed of the post-acceleration system and the OPR. The ion flight in the

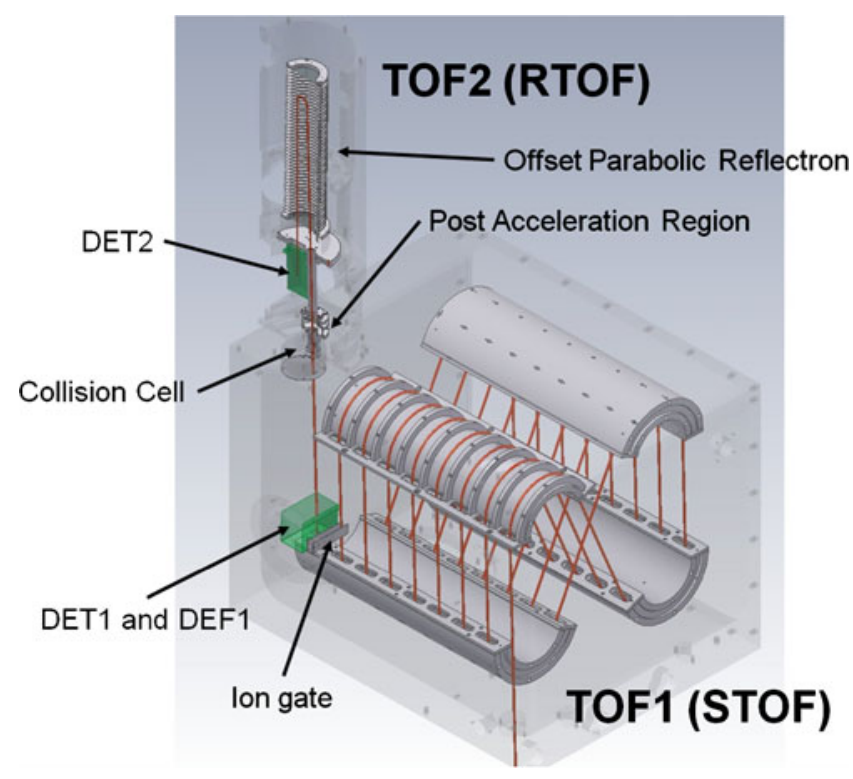

Figure 1. Schematic of time-of-flight mass spectrometer with spiral ion trajectory (STOF)/reflectron time-of-flight mass spectrometer (RTOF). The outer electrode of the left-top electrode in STOF is not included in the shown ion trajectory (red). The eight-cycle STOF, collision cell, and RTOF including an offset parabolic ion reflectron are arranged in tandem. The ion gate is set at the end of the seventh cycle, i.e., $15 \mathrm{~m}$ from the ion source
STOF has been described in reference [20]. The laser for ionization was changed to a Nd:YLF laser (wavelength: $349 \mathrm{~nm}$, model Explorer 349; Newport, CA, USA) from the nitrogen laser described in reference [20]. For acquiring a mass spectrum, the ions generated by the MALDI source (not shown in Figure 1) were accelerated to $20 \mathrm{keV}$, passed through the STOF, and detected by a secondary ion multiplier [DET1; DM291 (ETP, New South Wales 2114 Australia)]. The flight path from the ion source to the DET1 was $17 \mathrm{~m}$. When acquiring a product ion spectrum, the DET1 moved out from the trajectory to pass ions into the collision cell. The first deflector system (DEF1) was placed just after the DET1 in order to adjust the direction of the ions to the collision cell. The precursor ions were introduced into the collision cell without deceleration so that their collision energy was maintained at $20 \mathrm{keV}$. The ion gate for precursor ion selection was placed at the end of the seventh cycle, i.e., $15 \mathrm{~m}$ from the ion source. The ion gate consisted of a pair of $4 \mathrm{~mm} \varphi$ rod electrodes, whose centers were $7 \mathrm{~mm}$ apart from each other. The applied voltages to rod electrodes were $+925 \mathrm{~V}$ and $-925 \mathrm{~V}$ when the ion gate was closed; the voltages were turned to $0 \mathrm{~V}$ when the ion gate was opened.

\section{Collision Cell}

The collision cell was a $20 \mathrm{~mm}$ cylindrical tube with $2 \mathrm{~mm} \varphi$ entrance and exit apertures. It was placed at the center of a $40 \mathrm{~mm}$-long collision chamber that was separated from the TOF 1 and TOF 2 chambers by $3 \mathrm{~mm} \varphi$ apertures. All the chambers were evacuated by turbomolecular pumps. The vacuum was changed from $1 \times 10^{-5} \mathrm{~Pa}$ to $1 \times 10^{-4} \mathrm{~Pa}$ after helium gas was introduced for use as the collision gas.

\section{Ion Optical System of TOF2}

The TOF2 consists of a post-acceleration region, a field-free region (FFR), the OPR, and a secondary ion multiplier DET2 [148821 (ETP, Australia)]. The potential design of the TOF2 is shown in Figure 2. The TOF at each region was calculated by considering that single charged ions are generated by a MALDI ion source. Each potential was considered on the basis of the FFR in the following discussion. The TOF in the reacceleration region, $T_{p a}$, is given by

$$
T_{p a}=\sqrt{\frac{2 m}{e}} \frac{L_{p a}}{V_{p a}}\left(\sqrt{U+V_{p a}}-\sqrt{U}\right)
$$

Here, $e$ is the elemental charge; $m$, the ion mass; $L_{p a}$, the length of the post-acceleration region; $V_{p a}$, the potential of the post-acceleration region; and $e U$, the kinetic energy of an injected ion. The TOF in the FFR region, $T_{f}$, is given by

$$
T_{f}=\sqrt{\frac{2 m}{e}} \frac{L_{f}}{2} \sqrt{\frac{1}{U+V_{p a}}}
$$




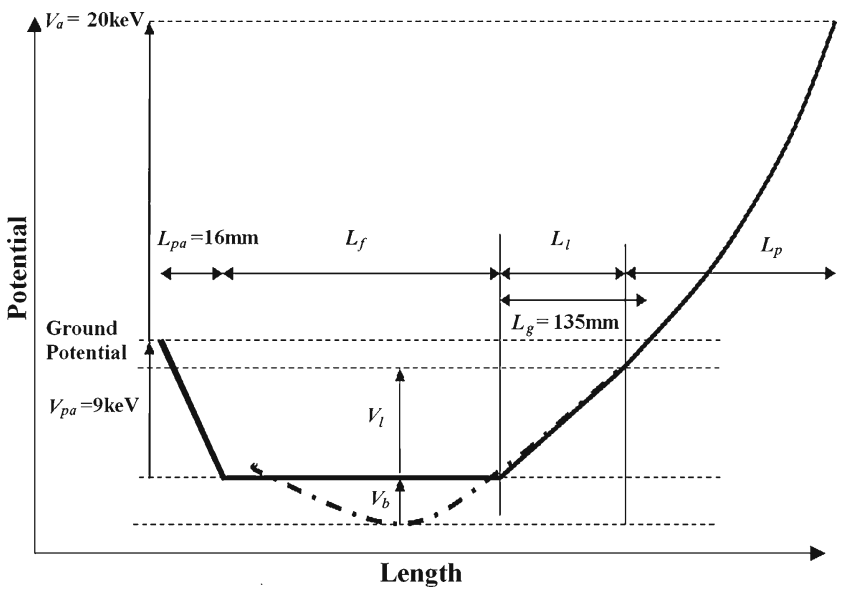

Figure 2. Potential design of TOF2; a post-acceleration region, field free region (FFR), and offset parabolic reflectron (OPR), which has linear and the parabolic parts, are shown. The values shown in the figure are from the calculated optimum potential design of the TOF2

Here, $L_{f}$ is the FFR length. The TOF in the linear part of the OPR, $T_{l}$, is

$$
T_{l}=\sqrt{\frac{2 m}{e}} \frac{2 L_{l}}{V_{l}}\left(\sqrt{U+V_{p a}}-\sqrt{U+V_{p a}-V_{l}}\right)
$$

Here, $L_{l}$ is the length of the linear part of the OPR, and $V_{l}$ is the boundary potential at the linear and parabolic parts of the OPR. The potential of the parabolic part of the OPR is defined as follows:

$$
V=\alpha x^{2}+V_{b}
$$

In (4), constant $a$ is given by

$$
\alpha=\left(\frac{\sqrt{V_{p a}-V_{b}}-\sqrt{V_{l}-V_{b}}}{L_{g}-L_{l}}\right)^{2}
$$

Here, $V_{b}$ is the local minimum value, and $L_{g}$ is the distance between the entrance and the position at ground potential in the OPR. The TOF in the parabolic part of the OPR, $T_{p}$, is given by

$$
T_{p}=\sqrt{\frac{2 m}{e}} \sqrt{\frac{1}{\alpha}}\left(\frac{\pi}{2}-\sin ^{-1} \frac{\sqrt{V_{l}-V_{b}}}{\sqrt{U+V_{p a}-V_{b}}}\right)
$$

The parameters in the ion optical system of the TOF2 were determined by employing the following method. First,

Table 1. Optimum Parameters of TOF2

\begin{tabular}{ll}
\hline$L_{p a}$ & $16 \mathrm{~mm}$ \\
$L_{f}$ & $331.27 \mathrm{~mm}$ \\
$L_{l}$ & $126.45 \mathrm{~mm}$ \\
$L_{p}$ & $225.12 \mathrm{~mm}$ \\
$L_{g}$ & $135.00 \mathrm{~mm}$ \\
$V_{p a}$ & $9000.00 \mathrm{~V}$ \\
$V_{l}$ & $8422.44 \mathrm{~V}$ \\
$V_{b}$ & $-1623.74 \mathrm{~V}$ \\
\hline
\end{tabular}

$V_{p a}, V_{l}$, and $V_{b}$ are based on the FFR values

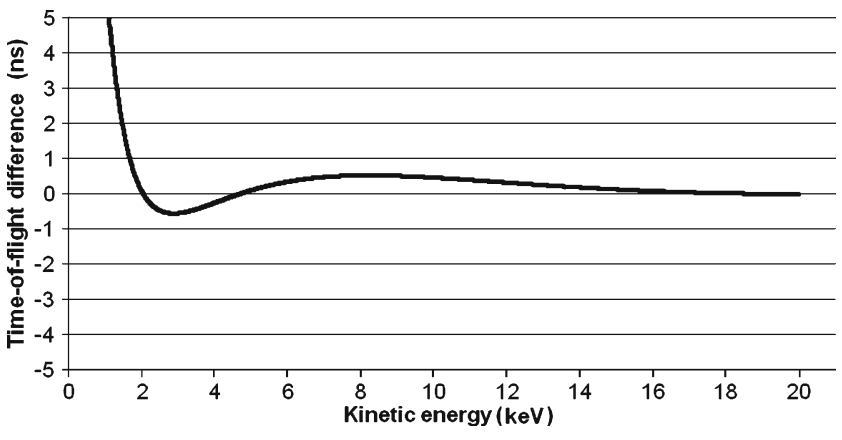

Figure 3. Relationship between kinetic energy and time-offlight of ions based on that for a $20 \mathrm{keV}$ ion

the following limitations were imposed: (1) the kinetic energy of the injected ion is given by $e U=(m / M) \times$ $e V_{a}=0-20 \mathrm{keV}$, where $m$ and $M$ are the masses of the fragment and precursor ion, respectively, and $V_{a}$ is the acceleration voltage at the ion source; (2) the postacceleration voltage $V_{p a}$ is $9 \mathrm{kV}$; (3) the length of the postacceleration region, $L_{p a}$, is maintained at $16 \mathrm{~mm}$, in order to ensure small differences in the electric field around the grid electrodes so that ion scattering by a lens effect is avoided; (4) $L_{g}$ is $135 \mathrm{~mm}$, which implies that the total OPR length is

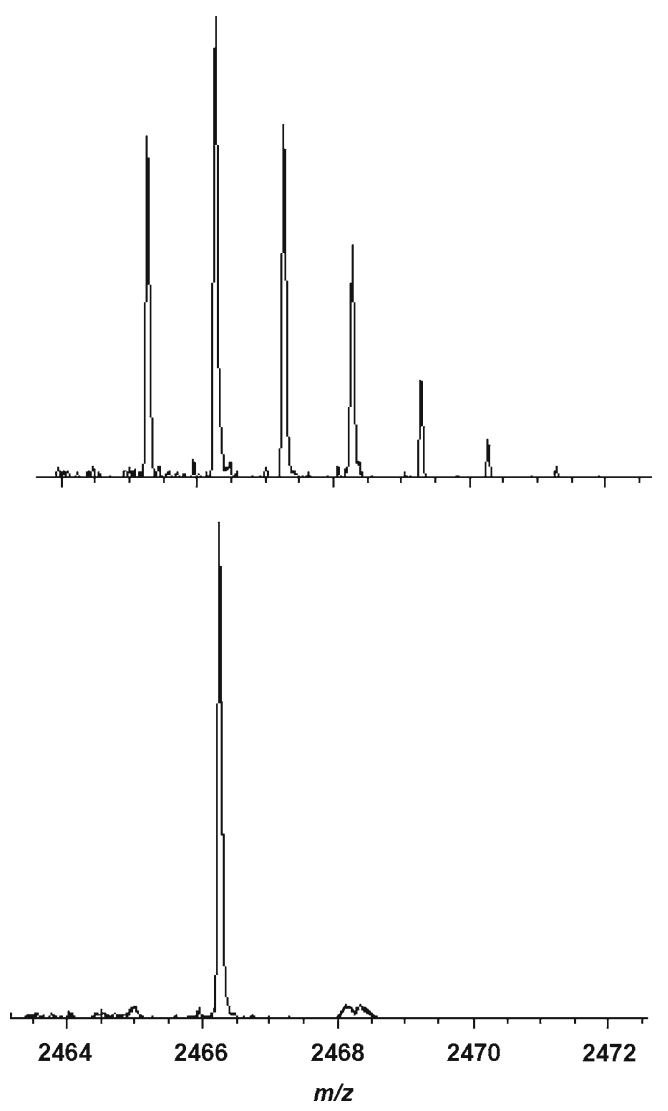

Figure 4. Precursor ion selectivity at $\mathrm{m} / \mathrm{z} 2466$. The top and bottom spectra represent the spectrum before and after the selection of the ACTH fragment 18-39 ( $\mathrm{m} / \mathrm{z} 2466)$, respectively 
Table 2. The Calibration Constants Used for (a) Internal and (b) External Calibrations

\begin{tabular}{lll}
\hline TOF range & Calibration constant & \\
\hline (a) Internal calibration constant & & \\
$<T_{\mathrm{n}}$ & $\mathrm{A}_{\mathrm{n}-1}$ & $\mathrm{~B}_{\mathrm{n}-1}$ \\
$T_{\mathrm{n}}-T_{\mathrm{n}-1}$ & $\mathrm{~A}_{\mathrm{n}-1}$ & $\mathrm{~B}_{\mathrm{n}-1}$ \\
$T_{\mathrm{n}-1}-T_{\mathrm{n}-2}$ & $\mathrm{~A}_{\mathrm{n}-2}$ & $\mathrm{~B}_{\mathrm{n}-2}$ \\
$\ldots$ & $\ldots$ & $\ldots$ \\
$T_{2}-T_{1}$ & $\mathrm{~A}_{1}$ & $\mathrm{~B}_{1}$ \\
$T_{1}-T_{0}$ & $\mathrm{~A}_{0}$ & $\mathrm{~B}_{0}$ \\
$>T_{0}$ & $\mathrm{~A}_{0}$ & $\mathrm{~B}_{0}$ \\
$(\mathrm{~b})$ External calibration constant & & \\
$<\alpha \beta T_{n}$ & $\alpha \mathrm{A}_{\mathrm{n}-1}$ & $\mathrm{~B}_{\mathrm{n}-1} / \beta$ \\
$\alpha \beta T_{n}-\alpha \beta T_{n-1}$ & $\alpha \mathrm{A}_{\mathrm{n}-1}$ & $\mathrm{~B}_{\mathrm{n}-1} / \beta$ \\
$\alpha \beta T_{n-1}-\alpha \beta T_{n-2}$ & $\alpha \mathrm{A}_{\mathrm{n}-2}$ & $\mathrm{~B}_{\mathrm{n}-2} / \beta$ \\
$\ldots$ & $\ldots$ & $\ldots$ \\
$\alpha \beta T_{2}-\alpha \beta T_{1}$ & $\alpha \mathrm{A}_{1}$ & $\mathrm{~B}_{1} / \beta$ \\
$\alpha \beta T_{1}-\alpha \beta T_{0}$ & $\alpha \mathrm{A}_{0}$ & $\mathrm{~B}_{0} / \beta$ \\
$>\alpha \beta T_{0}$ & $\alpha \mathrm{A}_{0}$ & $\mathrm{~B}_{0} / \beta$ \\
\hline
\end{tabular}

approximately $350 \mathrm{~mm}$; (5) the first-order coefficient is given by

$$
\left.\frac{\partial T}{\partial U}\right|_{U=e V_{a}}=0
$$

where $T=T_{p a}+T_{f}+T_{l}+T$; and (6) the ratio of the electric field at the boundary of the linear and parabolic parts of the OPR is in the range of 0.98-1.02.

For optimizing the parameters $L_{l}, V_{l}$, and $V_{b}$, they were scanned in steps of $0.01 \mathrm{~mm}, 0.02 \mathrm{~V}$, and $0.02 \mathrm{~V}$, respectively. $L_{f}$ was calculated for each combination $\left(L_{l}\right.$, $\left.V_{l}, V_{b}\right)$ to meet the requirements of (5). Further, when a combination $\left(L_{b}, L_{f}, V_{b}, V_{b}\right)$ meets requirement (6), the timeof-flights of $m=1000$ ions with kinetic energy of $e U=0.01-$ $20.00 \mathrm{keV}$, in step of $0.01 \mathrm{keV}$, were calculated. If the potential design of the TOF2 is optimized, the TOF of the $20.00 \mathrm{keV}$ ion and the time-of-flights of the other ions will mostly be identical at $0.5 \mathrm{~ns}$ or less. The optimized parameters are listed in Table. 1, and the relationship between the kinetic energy of ions and their time-of-flight (based on the relationship for the $20 \mathrm{keV}$ ion) is shown in
Figure 3. The TOF distribution of $2-20 \mathrm{keV}$ ions was maintained within $\pm 0.5 \mathrm{~ns}$ so that an appropriate product ion spectrum across the entire mass range could be acquired.

\section{Sample Preparation}

Substance P, ACTH fragment 18-39, and poly(propylene glycol) (PPG) were purchased from Sigma Aldrich Co. (St. Louis, MO, USA). The matrix compound $\alpha$-cyano-4hydroxycinnamic acid (HCCA) was purchased from Wako Pure Chemical Industries, Ltd. (Osaka, Japan). Acetonitrile $(\mathrm{ACN})$ and trifluoroacetic acid (TFA) were also purchased from the same company.

HCCA was dissolved in 1:1 ACN/0.1\% TFA deionized water solution at a concentration of $10 \mathrm{mg} / \mathrm{mL}$. Substance $P$ and ACTH fragment $18-39$ were prepared by dilutions in a $0.1 \%$ TFA deionized water solution at a concentration of $10 \mathrm{pmol} / \mu \mathrm{L}$. In the case of Substance P and ACTH, the matrix and each analyte solution were mixed in the ratio of $1: 1(\mathrm{vol} / \mathrm{vol}) ; 0.5 \mu \mathrm{L}$ of the mixture was deposited on a MALDI sample plate made of stainless steel by the dried-droplet method. PPG and sodium iodide were prepared by dilution in deionized water solution at concentrations of 10 and $1 \mathrm{mg} / \mu \mathrm{L}$, respectively. PPG, HCCA, and sodium iodide solutions were mixed in the ratio of $1: 2: 1$, and $0.5 \mu \mathrm{L}$ of the mixture was deposited on the MALDI target plate by the dried-droplet method.

\section{Results and Discussion}

\section{Precursor Ion Selectivity}

The precursor ion selectivity is shown in Figure 4. The top and bottom mass spectra show all the ions; only ions with $\mathrm{m} / \mathrm{z} 2466$ of ACTH fragment 18-39 [M+ H] $]^{+}$passed through the ion gate, while ions with $\mathrm{m} / \mathrm{z} 2465$ and 2467 were clearly eliminated. The difference in the $\mathrm{m} / \mathrm{z}$ value before and after the selection was $<0.1 \mathrm{u}$ and, hence, the electric field of the ion gate did not influence the selected precursor ions.

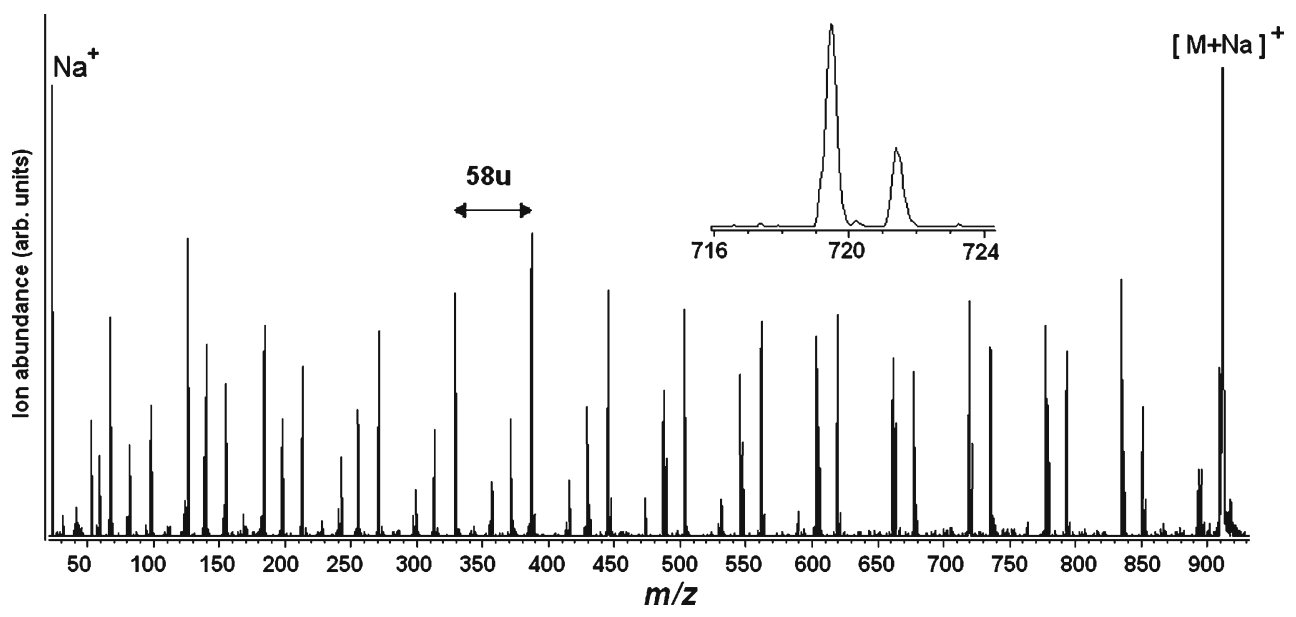

Figure 5. Product ion spectrum of PPG $\left([\mathrm{M}+\mathrm{Na}]^{+}, \mathrm{m} / \mathrm{z}\right.$ 911.6). The magnified spectrum at $\mathrm{m} / \mathrm{z} 716-724$ is also shown 
(a)

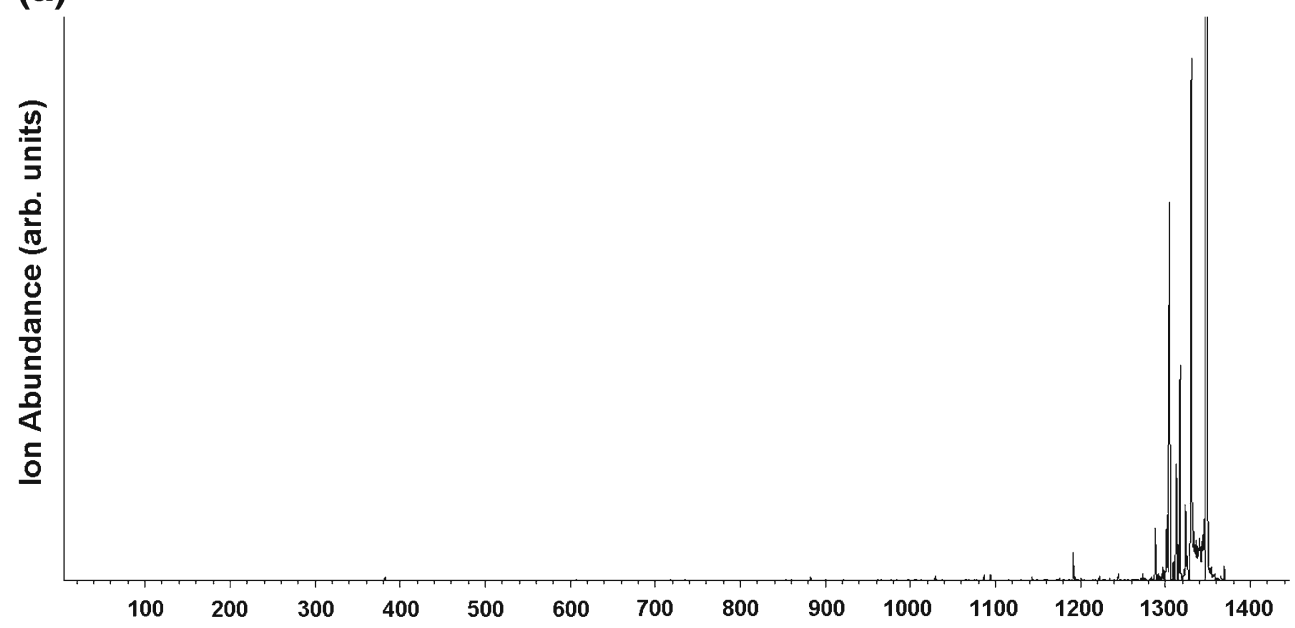

(b)

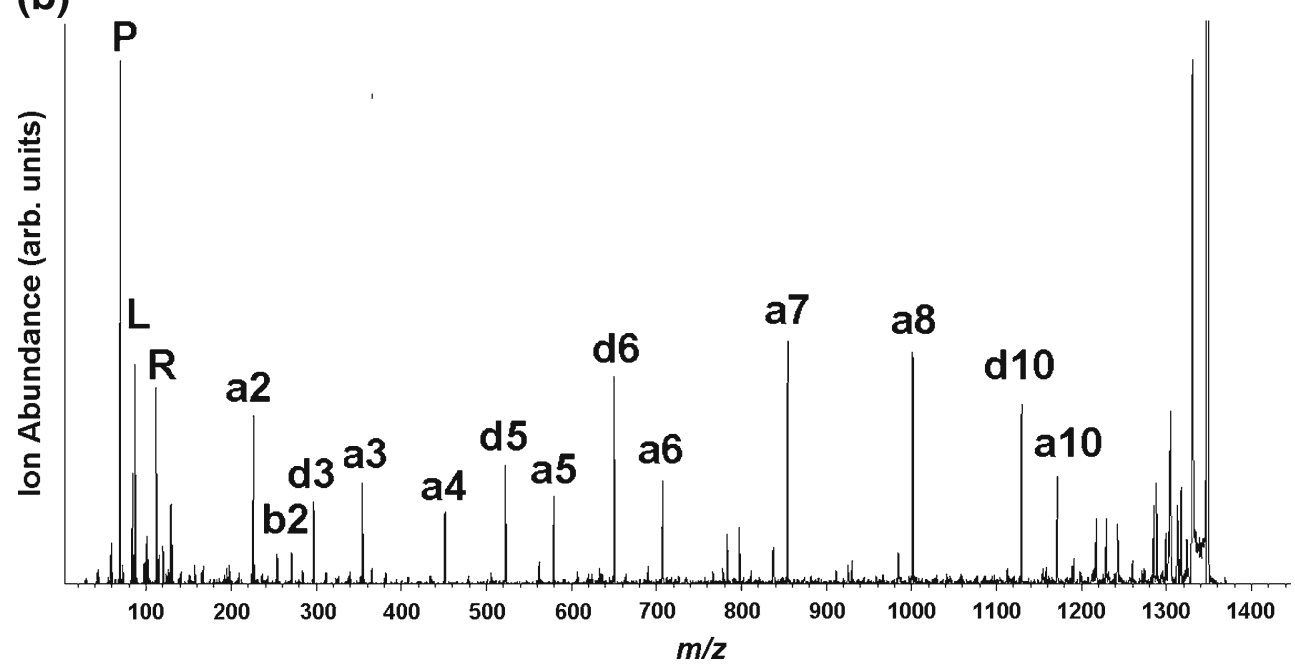

Figure 6. Product ion spectrum of Substance $\mathrm{P}\left([\mathrm{M}+\mathrm{H}]^{+}, \mathrm{m} / \mathrm{z}\right.$ 1347.7354): (a) without collision gas and (b) with collision gas

\section{Calibration Method for TOF2}

In this section, the internal and external calibration methods for TOF2 are discussed. For the internal calibration of TOF2, the time-of-flights and $m / z$ values of several fragment ions $\left(T_{N}, M_{N}\right)\left(N=1-n, T_{N}\right.$ and $M_{N}$ were increased according to a decrease in $N$ ) and those of a precursor ion $\left(T_{0}, M_{0}\right)$ were available. The time-of-flight region between $T_{n-1}$ and $\mathrm{T}_{n}$ was calibrated using the following first order equation:

$$
\sqrt{m} / z=\mathrm{A}_{n-1}+\mathrm{B}_{n-1} T
$$

where calibration constants $\mathrm{A}_{n-1}$ and $\mathrm{B}_{n-1}$ are expressed as

$$
\begin{gathered}
\mathrm{A}_{n-1}=\left(T_{n-1} \sqrt{M_{n}}-T_{n} \sqrt{M_{n-1}}\right) /\left(T_{n-1}-T_{n}\right) \\
\mathrm{B}_{n-1}=\left(\sqrt{M_{n-1}}-\sqrt{M_{n}}\right) /\left(T_{n-1}-T_{n}\right)
\end{gathered}
$$

Table 3. The Calculated $\mathrm{m} / \mathrm{z}$ Values, Observed $\mathrm{m} / \mathrm{z}$ Values, and Mass Errors of Fragment Pathways from Substance P

\begin{tabular}{lccr}
\hline & Calculated $m / z$ value & Observed $m / z$ value & Mass error \\
\hline $\mathrm{P}$ & 70.065 & 70.010 & -0.055 \\
$\mathrm{~L}$ & 87.092 & 87.019 & -0.073 \\
$\mathrm{R}$ & 112.087 & 112.025 & -0.062 \\
$\mathrm{a} 2$ & 226.166 & 226.217 & 0.051 \\
$\mathrm{~b} 2$ & 254.161 & 254.232 & 0.070 \\
$\mathrm{~d} 3$ & 297.203 & 297.272 & 0.069 \\
$\mathrm{a} 3$ & 354.261 & 354.242 & -0.019 \\
$\mathrm{a} 4$ & 451.314 & 451.355 & 0.041 \\
$\mathrm{~d} 5$ & 522.351 & 522.388 & 0.037 \\
$\mathrm{a} 5$ & 579.373 & 579.354 & -0.018 \\
$\mathrm{~d} 6$ & 650.410 & 650.420 & 0.011 \\
$\mathrm{a} 6$ & 707.431 & 707.471 & 0.040 \\
$\mathrm{a} 7$ & 854.500 & 854.489 & -0.010 \\
a8 & 1001.568 & 1001.465 & -0.103 \\
$\mathrm{~d} 10$ & 1129.563 & 1129.598 & 0.035 \\
$\mathrm{a} 10$ & 1171.674 & 1171.582 & -0.092 \\
\hline
\end{tabular}


The calibration constants used in each time-of-flight region are listed in Table $2 \mathrm{a}$.

For the external calibration of TOF2, the observed time-of-flight $T_{p}$ and the $\mathrm{m} / \mathrm{z}$ value $M_{p}$ of the precursor ion were available. The calibration constants calculated by the internal calibration method were corrected so that the observed $\mathrm{m} / \mathrm{z}$ value of the precursor ion would be $M_{p}$. The calibration constants for each time-of-flight region are listed in Table $2 b$, where the corrected constants $\alpha$ and $\beta$ were

$$
\begin{gathered}
\alpha=\sqrt{M_{p}} / \sqrt{M_{0}} \\
\beta=T_{p} \sqrt{M_{0}} / T_{0} \sqrt{M_{p}}
\end{gathered}
$$

\section{Product Ion Mass Spectrum}

In this section, the typical product ion spectra are shown. About 1000-2000 laser shots were used to produce each spectrum for observing low-intensity fragment pathways. A product ion spectrum of PPG $\left([\mathrm{M}+\mathrm{Na}]^{+}, m / z\right.$ 911.6) is shown in Figure 5. The fragment pathways indicating a repeated PPG monomer unit structure (58 u interval) were observed from $\mathrm{Na}^{+}(m / z$ 23) to the precursor ion. A magnified spectrum of $\mathrm{m} / \mathrm{z} 716-724$, which shows $2 \mathrm{u}$ separated peaks indicating different fragment pathways, is also shown. The mass resolution (full width half maximum) was about two or three times larger than the $\mathrm{m} / \mathrm{z}$ values in the entire mass range so that the sufficiently high mass resolutions for unit mass separation were achieved.

The product ion spectra of Substance P $\left([\mathrm{M}+\mathrm{H}]^{+}, m / z\right.$ 1347.7354) without and with a collision gas are shown in Figure 6a and b, respectively. In Figure 6a, few peaks were observed because the STOF eliminated the PSD ions. On the other hand, the a-series and d-series ions are observed in Figure $6 \mathrm{~b}$. The calculated $\mathrm{m} / \mathrm{z}$ values, observed $\mathrm{m} / \mathrm{z}$ values, and mass errors of the annotated fragment pathways shown in Figure $6 \mathrm{~b}$ are listed in Table 3. The observed $\mathrm{m} / \mathrm{z}$ values are calculated by the external calibration method. First, the internal calibration constants were calculated using the fragment pathways of PPG described above. They were then corrected using the observed time-of-flight and calculated $\mathrm{m} / \mathrm{z}$ value of the monoisotopic peak of Substance P. The mass accuracy of TOF2 was $<0.1$ unit.

\section{Discussion}

In our study, we have focused on developing a MALDISTOF/RTOF that can display a simple product ion spectrum with HE-CID fragment pathways. Our MALDI-STOF/ RTOF is based on the following three concepts: (1) selection of monoisotopic ions, (2) elimination of PSD ions, and (3) optimization of the TOF2.

From the results shown in Figure 4, it is clear that our system can select monoisotopic ions for $\mathrm{m} / \mathrm{z}=2500$. Since the time-of-flight difference at the ion gate between the masses of $\mathrm{M}$ and $\mathrm{M}+1$ ions increases as $\mathrm{M}$ decreases, monoisotopic ions less than $\mathrm{m} / \mathrm{z} 2500$ can also be selected. Furthermore, due to the monoisotopic ion selection and sufficiently high mass resolution of the TOF2, the fragmentation pathways of close $\mathrm{m} / \mathrm{z}$ values, such as the case shown in the magnified spectrum in Figure 5, are separated properly. Note that in contrast, in the same situation when MALDI-LTOF/RTOF is used, each fragment pathway appears with an isotope pattern and overlaps each other due to poor precursor ion selectivity. Hence, it becomes difficult to identify the fragmentation pathways of close $\mathrm{m} / \mathrm{z}$ values, especially those of large $\mathrm{m} / \mathrm{z}$ values.

A PSD product ion spectrum of the Substance P using MALDI-LTOF/RTOF has been shown in reference [22]. The ability of our system to eliminate PSD ions can be confirmed by comparing Figure 5a in reference [22] with Figure $6 \mathrm{a}$ in this paper. In contrast, the HE-CID fragment pathways of the a- and d-series ions were similar to those obtained for $20 \mathrm{keV}$ CID using MALDI-LTOF/RTOF and for $7 \mathrm{keV}$ CID using tandem sector instruments. Furthermore, by optimizing the TOF2 design, we could record the product ion spectra across the entire mass range. The immonium ions of Substance $\mathrm{P}\left([\mathrm{M}+\mathrm{H}]^{+}\right)$and the sodium ion generated from PPG $\left([\mathrm{M}+\mathrm{Na}]^{+}\right)$could also be observed in the product ion spectra.

\section{References}

1. Schey, K.L., Cooks, R.G.: A tandem time-of-flight mass spectrometer for surface-induced dissociation. Int. J. Mass Spectrom. Ion Processes 77, 49-61 (1987)

2. Schey, K.L., Cooks, R.G.: Ion/surface collision phenomena in an improved tandem time-of-flight instrument. Int. J. Mass Spectrom. Ion Processes 94, 1-14 (1989)

3. Cornish, T.J., Cotter, R.J.: Tandem time-of-flight mass spectrometer. Anal. Chem. 65, 1043-1047 (1993)

4. Seeterlin, M.A., Vlasak, P.R., Beussman, D.J., McLane, R.D., Enke, C. G.: High efficiency photo-induced dissociation of precursor ions in a tandem time-of-flight mass spectrometer. J. Am. Soc. Mass Spectrom. 4, $751-754$ (1993)

5. Beussman, D.J., Vlasak, P.R., McLane, R.D., Seeterlin, M.A., Enke, C. G.: Tandem reflectron time-of-flight mass spectrometer utilizing photodissociation. Anal. Chem. 67, 3952-3957 (1995)

6. Cornish, T.J., Cotter, R.J.: A curved-field reflectron for improved energy focusing of product ions in time-of-flight mass spectrometry. Rapid Commun. Mass Spectrom. 7, 1037-1040 (1993)

7. Medzihradszky, K., Campbell, J.M., Baldwin, M.A., Falick, A.M., Juhasz, P., Vestal, M.L., Burlingame, A.L.: The characteristics of peptide collision-induced dissociation using a high-performance MALDI-TOF/TOF tandem mass spectrometer. Anal. Chem. 72, 55558 (2000)

8. Yergey, A.L., Coorssen, J.R., Backlund Jr., P.S., Blank, P.S., Humphrey, G.A., Zimmerberg, J., Campbell, J.M., Vestal, M.L.: De novo sequencing of peptides using MALDI/TOF-TOF. J. Am. Soc. Mass Spectrom. 13, 784-791 (2002)

9. Schnaible, V., Wefing, S., Resemann, A., Suckau, D., Bücker, A., Wolfe-Kümmeth, S., Hoffmann, D.: Screening for disulfide bonds in proteins by MALDI in-source decay and LIFT-TOF/TOF-MS. Anal. Chem. 74, 4980-4988 (2002) 
10. Cotter, R.J., Gardner, B.D., Iltchenko, S., English, R.D.: Tandem timeof-flight mass spectrometry with a curved field reflectron. Anal. Chem. 76, 1976-1981 (2004)

11. Cornish, T.J., Cotter, R.J.: A curved field reflectron time-of-flight mass spectrometer for the simultaneous focusing of metastable product ions. Rapid Commun. Mass Spectrom. 8, 781-785 (1994)

12. Cordero, M.M., Cornish, T.J., Cotter, R.J., Lys, I.A.: Sequencing peptides without scanning the reflectron: post-source decay with a curved-field reflectron time-of-flight mass spectrometer. Rapid Commun. Mass Spectrom. 9, 1356-1361 (1995)

13. Kaufmann, R., Spengler, B., Lützenkirchen, F.: Mass spectrometric sequencing of linear peptides by product-ion analysis in a reflectron time-of-flight mass spectrometer using matrix-assisted laser desorption ionization. Rapid Commun. Mass Spectrom. 7, 902-910 (1993)

14. Kaufmann, R., Kirsch, D., Spengler, B.: Sequencing of peptides in a time-of-flight mass spectrometer: evaluation of post source decay following Matrix-Assisted Laser Desorption Ionization (MALDI). Int. J. Mass Spectrom. Ion Processes 131, 355-385 (1994)

15. Wysocki, V.H., Kenttamaa, H.I., Cooks, R.G.: Internal energy distributions of ions activated by various methods. Int. J. Mass Spectrom. Ion Processes 75, 181-208 (1987)

16. McLuckey, S.A.: Principles of collisional activation in analytical mass spectrometry. J. Am. Soc. Mass Spectrom. 3, 599-614 (1992)
17. Hill, J.A., Biller, J.E., Martin, S.A., Biemann, K., Yoshidome, K., Sato, $\mathrm{K}$.: Design considerations, calibration, and applications of an array detector for a four-sector tandem mass spectrometer. Int. J. Mass Spectrom. Ion Processes 92, 211-230 (1989)

18. Satoh, T., Tsuno, H., Iwanaga, M., Kammei, Y.: The design and characteristic features of a new time-of-flight mass spectrometer with a spiral ion trajectory. J. Am. Soc. Mass Spectrom. 16, 19691975 (2005)

19. Satoh, T., Tsuno, H., Iwanaga, M., Kammei, Y.: A new spiral time-offlight mass spectrometer for high mass analysis. J. Mass Spectrom. Soc. Jpn. 54(1), 11-17 (2006)

20. Satoh, T., Sato, T., Tamura, J.: Development of a high-performance MALDI-TOF mass spectrometer utilizing a spiral ion trajectory. J. Am. Soc. Mass Spectrom. 18, 1318-1323 (2007)

21. Nikolaev, E.N., Somogyi, Á., Smith, D.L., Gu, C., Wysocki, V.H., Martin, C.D., Samuelson, G.L.: Implementation of low-energy surfaceinduced dissociation (eV SID) and high-energy collision-induced dissociation ( $\mathrm{keV} \mathrm{CID})$ in a linear sector-TOF hybrid tandem mass spectrometer. Int. J. Mass Spectrom. 212, 535-551 (2001)

22. Pittenauer, E., Allmaier, G.: High-energy collision induced dissociation of biomolecules: MALDITOF/RTOF mass spectrometry in comparison to tandem sector mass spectrometry. Combinat. Chem. High Throughput Screen 12, 137-155 (2009) 